\title{
Regulation and practice of workers' protection from chemical exposures during container handling
}

Randi Nørgaard Fløe Pedersen', Jørgen Riis Jepsen ${ }^{1}$ and Balázs Ádám ${ }^{1,2^{*}}$

\begin{abstract}
Background: Fumigation of freight containers to prevent spread of pests and off-gassing of freight are sources of volatile chemicals that may constitute significant health risks when released. The aim of the study was to investigate the regulation and practice of container handling in Denmark with focus on preventive measures to reduce risk of chemical exposure.

Methods: A comprehensive systematic search of scientific literature, legislation and recommendations related to safe work with transport containers from international and Danish regulatory bodies was performed. The practice of handling containers was investigated in a qualitative study based on a series of semi-structured interviews with key informants, including managers and health and safety representatives of organizations that handle containers.

Results: Although several international and national regulations and local safety instructions relate to container handling, the provided information is not sufficiently detailed to conduct safe practice in many aspects. In accordance with the scientific literature, the interviewees estimate that there is a high frequency (5 to 50\%) of containers with hazardous chemical exposure that are regarded as potentially damaging to health, although recognisable health effects are rare. There is limited knowledge about the types of chemicals, which mostly cannot be measured by available devices at the worksite. Aeration and use of personal protective equipment are typical preventive measures in practice, but their use is not consistent and does not necessarily ensure adequate protection.

Conclusions: Managers, workers, even occupational health professionals have limited knowledge about the hazardous chemicals that can be released from containers. Detailed risk assessment and specific instructions on risk management are needed for safe handling of transport containers.
\end{abstract}

Keywords: Transport container, Chemical exposure, Fumigation

\section{Background}

Residues of toxic industrial chemicals and pesticide fumigants in freight containers can expose employees and customers all over the world [1]. Fumigation is a widely used method to prevent a multitude of pests, i.e. fungi and arthropods, from destroying natural products and spread worldwide during transport [2]. Previous studies in the harbours of Hamburg and Rotterdam have identified high frequencies of containers contaminated with fumigants

\footnotetext{
* Correspondence: badam@uaeu.ac.ae

${ }^{1}$ Centre of Maritime Health and Society, Institute of Public Health, University of Southern Denmark, Esbjerg, Denmark

${ }^{2}$ Institute of Public Health, College of Medicine and Health Sciences, United Arab Emirates University, Al Ain, United Arab Emirates
}

and other industrial chemicals, such as methyl bromide and formaldehyde, the concentration of which in many cases exceeded the chronic recommended exposure levels [1,3]. Inspections of containers unloaded in ports have shown that many containers have gone through a previous treatment with fumigants, which was not documented. Even containers declared as ventilated may still have a high concentration of hazardous chemicals inside when opened. A study in the Netherlands detected methyl bromide, formaldehyde and phosphine in $21 \%$ of containers that were typically not declared as chemically treated [4]. The rare occurrence of adequate labelling was also noted in the Port of Hamburg [5]. 
These observations show that caution has to be taken when handling containers, especially if transported in international trade.

The 2009 International Standards for Phytosanitary Measures No. 15 of the International Plant Protection Convention defines how packing materials used in international trade must be treated for preventing spread and deterioration caused by pests [6,7]. Traditionally, methyl bromide is the chemical that is used for the fumigation of containers. However, methyl bromide is to be gradually phased out by the requirements of the Montreal Protocol on Substances that Deplete the Ozone Layer and the Integrated Pollution Prevention and Control recommendation for the replacement of methyl bromide $[8,9]$. The phasing out of methyl bromide led to the introduction of other chemical substances for fumigation of transport containers.

In addition to the exposures relating to the fumigation process in the supplier countries, employees can be exposed to toxic gasses when inspecting and unpacking containers in the port of arrival or when unloading containers at the final destination of the imported goods [10]. The fumigants most frequently detected in freight containers are methyl bromide, hydrogen phosphide, ethylene dichloride, trichloronitromethane, chloropicrin and ethylene oxide. Organic solvents, such as toluene, styrene and benzene, as well as other industrial chemicals, such as formaldehyde, are also frequently reported pollutants in containers $[1,7,11,12]$. The characteristics of the chemicals, such as toxicity, flammability, volatility, and relative persistence, determine the level of risk they impose on human health [7]. Some of the chemicals are extremely flammable, such as hydrogen phosphide and ethylene oxide. The symptoms of toxic effects predominantly observed in exposed workers are headache, dizziness, nausea, skin and mucous membrane irritation, and concentration and memory problems [3,10,12]. The main targets of toxic effect are the respiratory and the nervous system. Ethylene oxide, formaldehyde and benzene can damage DNA and induce cancer as recognised by the International Agency for Research on Cancer, while some fumigants, such as methyl bromide, are suspected carcinogens [2,13-15].

Although opening, inspecting and unloading containers may pose considerable level of health risk to the workers as they are exposed to chemicals, especially if the container has previously been fumigated, we know very little about the health and safety measures in practice of these work activities. The aim of this descriptive study is to investigate the regulation and practice of container handling in Denmark with a focus on the adequacy of regulations to guide safe practice and the effectiveness of preventive measures applied to reduce the risk of chemical exposure.

\section{Methods}

A comprehensive review of the international and Danish regulations that are relevant to preventing chemical exposures released from transport containers was performed. The systematic search included the review of webs-based public domains of international organisations, such as the International Labour Organization (ILO), the International Maritime Organization (IMO), and the European Union (EU), as well as of Danish national regulatory bodies. Links between the regulations at international and national level were identified using information e.g. on the extent to which EU regulations are implemented in different EU member states, including Denmark.

To study the local safety instructions and practice of container handling in Denmark with regard to prevention from potential chemical exposures, an explorative survey of qualitative study design was executed [16]. Interviews were conducted with nine managers and occupational health and safety representatives of organisations that carry out inspection or unloading of transport containers in Danish harbours. The selection of respondents was based on a purposeful snowball sampling method of individuals that were deemed to be rich in information and experiences related to the topic [16]. The conducted interviews flexibly followed a template that included questions about work activities, potential chemical exposures, experienced health effects, health and safety regulations and applied preventive measures (Additional file 1). This semistructured face-to-face method was used to support the respondents to share their views and to gain in-depth information about the topic. The interviews were performed at the site of the establishment. Notes and voice records were taken during the conversations. Information extracted from the notes and records was transcribed to a database. The summarised data were qualitatively described and analysed in relation to the results of the review of regulations.

\section{Results}

\section{Regulations to prevent harmful chemical exposures during container handling}

Several regulations identified on international and national level have relevance to the prevention of chemical exposures during container handling. The regulations and their relationships are illustrated in Figure 1.

The central instruments of the ILO (Occupational Safety and Health Convention No. 155 and Occupational Safety and Health Recommendation No. 164), the European Framework Directive on Safety and Health at Work (89/ 391/EEC), and the Danish Working Environment Act (LBK no. 1072 of 07/09/2010) draw the principles for protecting workers' health. Both on EU and national level, additional specific regulations can be identified as relevant to container handling. These regulations concern general 


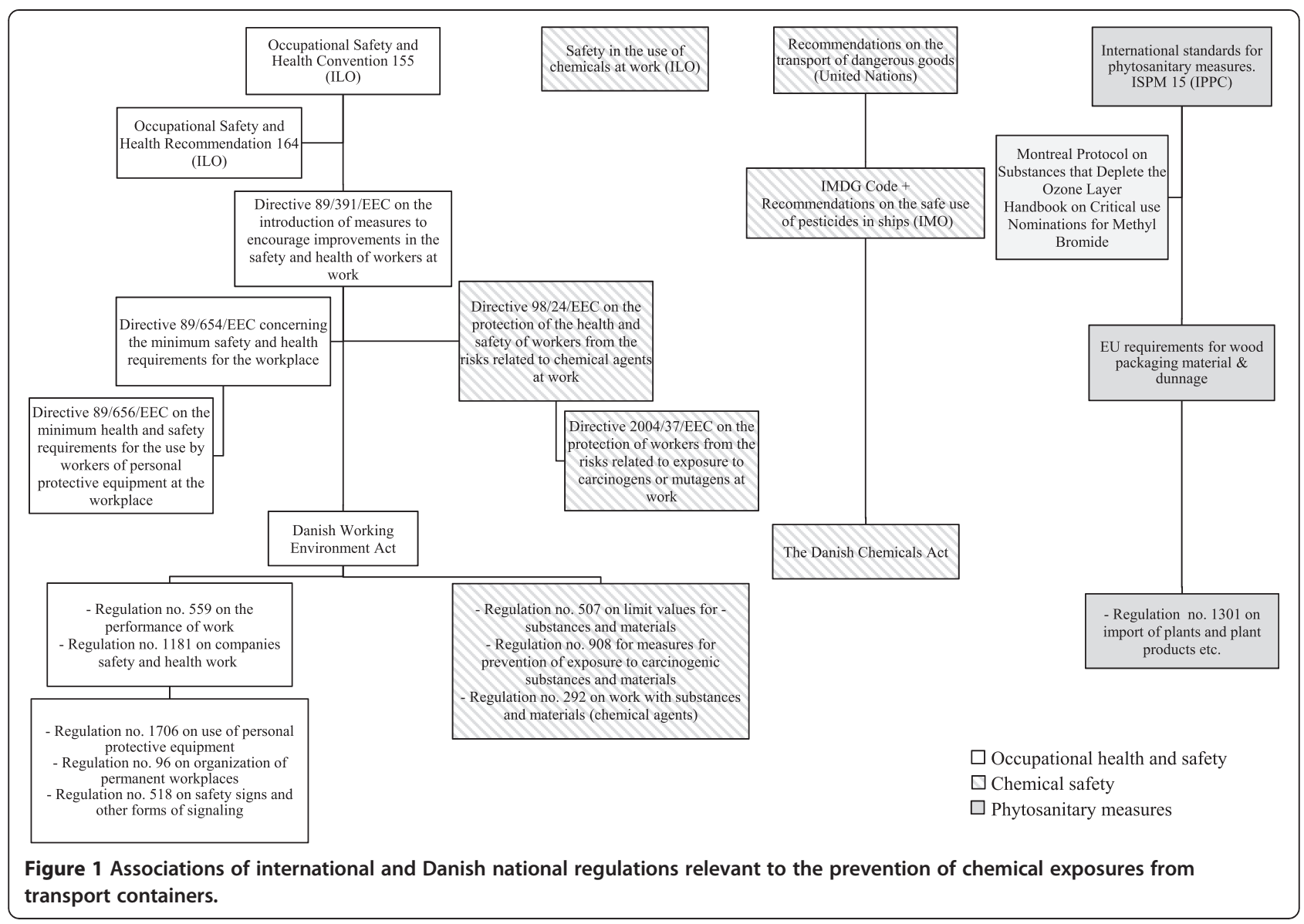

aspects of occupational health and safety as well as use of preventive measures to protect workers from chemical exposures at the workplace, including engineering control, administrative measures and personal protective equipment.

Legal instruments dealing with chemical safety and use of chemicals at workplaces can substantially influence the risk of chemical exposure from transport containers. The purpose of the ILO code of practice "Safety in the use of chemicals at work" is to prevent or reduce the incidence of chemically induced occupational illnesses and injuries [17]. The United Nations' Recommendations on the Transport of Dangerous Goods states the basic requirements for the transportation of hazardous substances, while the International Maritime Dangerous Goods (IMDG) Code of IMO regulates the transport of dangerous goods by sea [18]. The IMDG Code covers issues such as packing, container transportation and stowage. The supplement of this Code includes the "Recommendations on the safe use of pesticides in ships" which closely relate to phytosanitory precautions in international trade. The International Plant Protection Convention has developed the International Standards for Phytosanitary Measures No. 15 (ISPM 15) which addresses treatment of the wood packing material that is used in connection with shipping of products between countries. This treatment is required for the prevention of spread of infestation [6]. ISPM 15 requires all wood packing material to be debarked and then heat treated or fumigated with methyl bromide. Following fumigation, an international mark declaring previous chemical treatment must be placed on the container. The EU requirements for wood packing materials are based on ISPM 15 [19].

The Danish Chemicals Act (LBK no. 878 of 26/06/ 2010) regulates the safe trading and use of chemical substances and products. If pesticides are used for treating freight in Danish ships or in foreign ships in Danish ports, the IMO Recommendations on the safe use of pesticides in ships must be followed as described in the IMDG Code [20]. The Danish regulation (Executive Order on imports of plants and plant products, etc. BEK no.1301 of 17/12/2012) follows the approved treatments specified in ISPM 15 on Guidelines for regulation of wood packaging material in international trade.

\section{Practice of container handling and prevention of chemical exposures}

The interviewed managers and occupational health and safety representatives of container handling companies 
provided an overview of the practice of working with transport containers. The interviewees gave information about the perceived level of risk from chemical exposure on the employees, experience of health effects related to chemical exposures, knowledge of applicable health and safety regulations, and about the preventive measures used in practice.

Two major working populations can potentially be exposed to hazardous chemicals when handling containers in Danish harbours. The first are the workers who unload freight from containers, the second are the government officers in charge of inspecting transported goods.

Unloading is a typically manual task with limited automation. Workers have to go inside the container and carry the goods by hand. In the event of inspection, an employee of the transporting company, e.g. the truck driver will usually open the container but the officer is the first to enter. The inspection often requires moving deep inside the container, climbing on boxes or partly unloading the freight. If unloading is necessary, it is carried out by the transporting company's workers and only rarely by the officers themselves.

In spite of limited knowledge about the potential health risks that chemical exposures from fumigated containers can pose on the employees who enter the containers, all the interviewees agreed on the existence of such exposures. They expressed the concern about frequent chemical exposure and estimated the proportion of containers polluted with hazardous chemicals to be in the range from $5 \%$ to as high as $50 \%$. According to their experiences, $20 \%$ to $50 \%$ of the containers have a distinct perceivable odour. In contrast, they recalled a very low - typically less than $5 \%$ - frequency of containers that are documented and labelled as previously fumigated or chemically treated. When asking about chemicals that can accumulate in containers, methyl bromide was the only one that all interviewed persons could quote. Some interviewees expressed their awareness about the occurrence of general industrial chemicals in containers but could not specify them. Situations where there appears to have been the potential for exposure were also mentioned. For example instances have been noted where white powder was detected in some containers and the identity of the powder was unknown.

Most of the interviewees assumed that chemical exposures from transport containers may damage workers' health if exposure occurred over a sustained period. Inspectors were reported to be increasingly aware of the risk, although their specific knowledge is still little. Manual workers continue to have a very limited understanding of the risk posed to them from chemical exposure in transport containers. Regardless of their level of knowledge, fear is not typical among the potentially exposed employees.
The most common acute health effect that can potentially be related to chemical exposures during container handling is headache. It was more frequently experienced in the past and tends to be related to special types of freights, such as rubber tyres. Eye irritation and unspecified discomfort are also experienced occasionally. However, none of the interviewees could remember chronic intoxications/occupational diseases with medically established connection to previous chemical exposures.

The interviewed managers were aware of the existence of relevant international and national regulations although they were typically not able to specify them. On the other hand, the interviewees were more knowledgeable about the local instructions of their organisations, which are based on the relevant international and national regulations and made available for the employees. Besides the general provisions for workplace health and safety, e.g. risk assessment, education, use of safety equipment and personal protective equipment, the local instructions, however, give insufficient guidance for several practical challenges of preventing chemical exposures during work with containers.

In practice, the measures applied in the approached container handling organisations to prevent harmful chemical exposures released from transport containers are primarily based on the attempt to identify the containers that carry occupational health risks. The review of documentation is reported to be the main way to get information about previous chemical treatment, although, as discussed above, such documentation is rarely seen and likely to be absent in a major proportion of containers that have been fumigated in the supplier country. Apart from the documents, strange odour, the type of goods and the country of origin may create suspicion. According to experiences, containers arriving from developing countries with food, footwear, furniture and other wood products may most frequently carry chemical hazards. Equipment for monitoring of container air is available in some of the organisations only, and even if available, the measuring device can detect only methyl bromide but no other potentially harmful chemicals. In some organisations a suspicion is sufficient for applying specific preventive measures while others would require positive results of air measurements to take action. Table 1 summarises the main preventive measures and the concerns related to their effectiveness in reducing chemical exposures to an acceptable level.

The decision and choice of preventive measures to be used in practice are often left to the directly involved employees and the actions taken show considerable variation. The main preventive measure to reduce chemical exposure is natural ventilation; active ventilation is not used in practice. The conditions of aeration are not consistently applied; the reported ventilation times vary 


\begin{tabular}{|c|c|c|}
\hline Preventive measure & Method & Concerns of application \\
\hline \multirow[t]{3}{*}{$\begin{array}{l}\text { Identification of } \\
\text { contaminated containers }\end{array}$} & $\begin{array}{l}\text { Review of documentation for previous chemical } \\
\text { treatment }\end{array}$ & $\begin{array}{l}\text { Chemical treatment of containers is rarely } \\
\text { documented (less than } 5 \% \text { are labelled) }\end{array}$ \\
\hline & $\begin{array}{l}\text { Suspicion generated by the odour, type of goods } \\
\text { and country of origin }\end{array}$ & $\begin{array}{l}\text { Suspicion is subjective, some of the hazardous } \\
\text { chemicals have no perceivable odour }\end{array}$ \\
\hline & Air monitoring & $\begin{array}{l}\text { Devices used in practice can measure only methyl } \\
\text { bromide but no other fumigants and typical industrial pollutants }\end{array}$ \\
\hline \multirow[t]{2}{*}{ Ventilation } & Passive ventilation (aeration) & $\begin{array}{l}\text { Aeration time varies ( } 2 \text { to } 48 \text { hours) and may not } \\
\text { be enough to reduce chemical concentration to a safe level }\end{array}$ \\
\hline & Active ventilation (extraction or inflation) & Not used in practice \\
\hline \multirow{5}{*}{$\begin{array}{l}\text { Personal protective } \\
\text { equipment }\end{array}$} & \multirow[t]{3}{*}{ Respiratory protection } & Filter masks are rarely used \\
\hline & & Dust masks do not provide adequate protection \\
\hline & & Limited use due to discomfort of wearing \\
\hline & Gloves & Limited use due to discomfort of wearing \\
\hline & Protective clothing & Limited use due to discomfort of wearing \\
\hline
\end{tabular}

between 2 and 48 hours without any knowledge of whether this amount of time is sufficient or not. The other major way of preventing adverse health effects of chemical exposures is the use of appropriate personal protective equipment. Although masks are usually provided to the workers, they are mainly dust masks that do not prevent exposure to chemical vapours. Suitable gloves are typically available, and the use of coveralls was also reported by some interviewees. In practice, however, the overall frequency of wearing personal protective equipment is low.

\section{Discussion}

Both international and national legislation provide a framework to prevent exposure to chemicals during the handling of freight containers in Denmark. The local safety instructions of container handling organisations illustrate a systematic approach towards the prevention of toxic chemical exposures at work. They are, however, not sufficiently specific in details with respect to the application of precautions aimed at protecting human health from chemical exposures in practice. The main concerns about practices where the guidance provided by regulations falls short are the identification of hazardous containers, the applied method of ventilation, and the appropriate use of adequate personal protective equipment.

This qualitative analysis of the regulations and practice of preventing exposure to harmful chemicals during container handling provides new information regarding the shortcomings in Denmark. Other nations would also benefit from scrutinising their own practices in this field of health and safety practice. Typical for qualitative research, the interview survey included a limited number of participants who may not represent all stakeholders and therefore the findings can only be generalised to the Danish context with caution. Nevertheless, the observations are consistent with those reported by the few studies that investigated occupational chemical exposures released from transport containers $[1,7,12]$. The interviewees' estimates of a high frequency of chemically contaminated containers is in line with the measurements carried out in the harbour of Hamburg that found $70 \%$ of freight containers to be contaminated with toxic chemicals above the chronic reference exposure level values [1]. Managers and occupational health and safety representatives assume that hazardous chemicals found in containers can potentially damage workers' health, although they perceive that recognisable health consequences are rare in practice. Considerable hidden morbidity of borderline cases and difficulty to establish causal relationship between an exposure and a disease with long preclinical phase might be explanations for the scarcity of diagnosing occupational diseases in relation to previous chemical exposures.

The implementation of the Montreal Protocol led to a reduction in the number of containers treated with methyl bromide, but at the same time, it resulted in the introduction of several new substances for container fumigation. Consequently, international regulations which aim to protect the environment may increase the risk of chemical exposure in employees who work in the freight container industry. A number of hazardous chemicals are detected in freight containers and this finding may explain the higher incidence of neurological and respiratory health effects observed among container workers [3,12]. The health hazards of some of these substances are still not entirely understood and there are no specific reporting schemes for health effects possibly related to chemical exposure during container handling.

Monitoring techniques used in practice are insufficient as they do not detect most of the harmful chemicals $[3,11]$. Although the detailed analysis of several chemicals requires 
sophisticated and expensive measurements, there are monitoring devices that are relatively simple to operate and can identify transport containers with high concentration of a wide range of hazardous substances. The main barrier of their use is the lack of sufficient knowledge about the problem itself and about the availability of proper monitoring equipment.

There are no adequate ventilation times specified for the aeration of containers. Required time depends on numerous factors, such as the type of hazardous chemical, type and amount of freight. Even 48-hour passive ventilation may not be sufficient in some cases [21]. Forced ventilation is more effective than aeration, especially with extraction fan, as proposed by Svedberg and Johanson [22].

\section{Conclusions}

Workers are potentially exposed to hazardous chemicals when handling transport containers and regulations do not provide adequate guidance to employers with respect to conducting safe practices. Based on these findings, it is essential to address the issue to relevant regulatory bodies so that they review the occupational health and safety regulations related to container handling to protect the employee both now and in the future. Several areas of practice, including identification of polluted containers by regular air monitoring with devices that can detect a broad range of hazardous chemicals, appropriate ventilation, biomonitoring and health surveillance, detailed risk assessment, informing workers about chemical risks, providing appropriate personal protective equipment and ensuring their adequate use warrant further scrutiny in order to ensure safe conditions for workers who handle transport containers.

\section{Additional file}

Additional file 1: Interview template.

\section{Competing interests}

The authors declare that they have no competing interests.

\section{Authors' contributions}

RNFP conducted the regulation review and prepared the first draft of the manuscript, JRJ gave professional advice for the study and contributed to manuscript preparation, BÁ supervised the study, conducted the interview survey and finalised the manuscript. All authors read and approved the final manuscript.

\section{Acknowledgements}

This work was supported by the UHH, CAU, SDU and AU collaboration initiative.

Received: 29 July 2014 Accepted: 17 September 2014

Published online: 23 September 2014

\section{References}

1. Baur X, Poschadel B, Budnik LT: High frequency of fumigants and other toxic gases in imported freight containers-an underestimated occupational and community health risk. Occup Environ Med 2010, 67:207-212.

2. Budnik LT, Kloth S, Velasco-Garrido M, Baur X: Prostate cancer and toxicity from critical use exemptions of methyl bromide: environmental protection helps protect against human health risks. Environ Health 2012, 11:5.

3. Preisser $A M$, Budnik $L T$, Baur $X$ : Health effects due to fumigated freight containers and goods: how to detect, how to act. Internat Marit Health 2012, 63:133-139.

4. Knol-de Vos T: Measuring the Amount of Gas in Import Containers. Report number 609021025/2003. Bilthoven: Rijksinstituut voor Volksgezondheid en Milieu (RIVM); 2002. Available at: http://rivm.openrepository.com/rivm/ bitstream/10029/9020/1/609021025.pdf, Accessed 17 July 2014.

5. Low A, Husing UP, Preisser A, Baur X: Regulations and control of in-transit fumigated containers as well as of fumigated cargo ships. Internat Marit Health 2003, 54:77-85.

6. International Plant Protection Convention: International Standards for Phytosanitary Measures ISPN 15 Regulations of Wood Packaging Material in International Trade (2009). Rome: IPCC, FAO; 2011

7. Budnik LT, Fahrenholtz S, Kloth S, Baur X: Halogenated hydrocarbon pesticides and other volatile organic contaminants provide analytical challenges in global trading. J Environ Monit 2010, 12:936-942.

8. United Nations Environment Programme: Montreal Protocol on Substances that Deplete the Ozone Layer. Nairobi: UNEP; 1987.

9. International Plant Protection Convention: Replacement or Reduction of the Use of Methyl Bromide as a Phytosanitary Measure, CPM-3/2008. Rome: IPPC; 2008.

10. Preisser AM, Budnik LT, Hampel E, Baur X: Surprises perilous: toxic health hazards for employees unloading fumigated shipping containers. Sci Total Environ 2011, 409:3106-3113.

11. Fahrenholtz S, Huhnerfuss H, Baur X, Budnik LT: Determination of phosphine and other fumigants in air samples by thermal desorption and 2D heart-cutting gas chromatography with synchronous SIM/Scan mass spectrometry and flame photometric detection. J Chromatogr A 2010, 1217:8298-8307.

12. Safe Work Australia: Hazard Surveillance: Residual Chemicals in Shipping Containers. Canberra: Safe Work Australia; 2012

13. Nagy K, Ádány R, Szücs S, Ádám B: Susceptibility of lung epithelial cells to alkylating genotoxic insult. Environ Mol Mutagen 2013, 54:682-689.

14. Swenberg JA, Moeller BC, Lu K, Rager JE, Fry RC, Starr TB: Formaldehyde carcinogenicity research: 30 years and counting for mode of action, epidemiology, and cancer risk assessment. Toxicol Pathol 2013, 41:181-189.

15. McHale CM, Zhang L, Smith MT: Current understanding of the mechanism of benzene-induced leukemia in humans: implications for risk assessment. Carcinogenesis 2012, 33:240-252.

16. Onwuegbuzie AJ, Leech NL: A call for qualitative power analyses. Qual Quant 2007, 41:105-121

17. International Labour Organization: Safety in the Use of Chemicals at Work. An ILO Contributions to the International Programme on Chemical Safety of UNEP, the ILO and the WHO (IPCS). Geneva: ILO; 1993.

18. International Maritime Organization: International Maritime Dangerous Goods (IMDG) Code. London: IMO; 2010.

19. European Commission: Requirements for Wood Packaging Material \& Dunnage. Brussels: EC; 2013. Available at: http://ec.europa.eu/food/plant/ plant_health_biosafety/trade_non_eu/wood_packaging_dunnage_en.htm, Accessed 17 July 2014

20. Danish Maritime Authority: Technical Regulation on the Use of Pesticides in Ships. Technical Regulation no. 9. Copenhagen: DMA; 2000.

21. Nordiko: Review of National Guidance Material for Working Safely on the Waterfront. Addendum to Submission by Nordiko Quarantine Systems Pty Ltd. . Available at: http://www.safeworkaustralia.gov.au/sites/SWA/model-whslaws/public-comment/Documents/National_Guidance_Material-Waterfront/ Public-Submissions-N/NGMW003-Nordiko_Addendum.PDF.

22. Svedberg $U$, Johanson $G$ : Work inside ocean freight containers-personal exposure to off-gassing chemicals. Ann Occup Hyg 2013, 57:1128-1137.

\section{doi:10.1186/s12995-014-0033-6}

Cite this article as: Pedersen et al:: Regulation and practice of workers' protection from chemical exposures during container handling. Journal of Occupational Medicine and Toxicology 2014 9:33. 